DOI: 10.12957/demetra.2015.13599

\title{
Repercussões das intervenções domiciliares na continuidade do aleitamento materno
}

\section{Repercussions of home interventions on the continuation of breasffeeding}

\author{
Bárbara Maldonado Tomazetti \\ Adriane Cervi Blümke² \\ Franceliane Jobim Benedetti \\ 1 Universidade Federal de Santa Maria, Programa \\ de Residência Multiprofissional em Saúde. Santa \\ Maria-RS, Brasil. \\ ${ }^{2}$ Centro Universitário Franciscano, Curso de \\ Nutrição. Santa Maria-RS, Brasil. \\ Correspondência / Correspondence \\ Adriane Cervi Blümke \\ Centro Universitário Franciscano. Curso de \\ Nutrição. Rua Silva Jardim, 1175, Conjunto III, \\ Prédio 17. CEP 97010-491, Santa Maria-RS, \\ Brasil \\ E-mail: adriblumke@yahoo.com.br
}

\section{Resumo}

O objetivo desta pesquisa foi avaliar as repercussões de intervenções domiciliares na continuidade do aleitamento materno. Trata-se de estudo experimental não randomizado, com coleta de dados e intervenção realizadas entre janeiro e julho de 2013. Participaram 20 nutrizes (11 no grupo intervenção e nove no grupo controle) que tiveram seus filhos em um hospital público do município de Santa Maria-RS, sendo acompanhadas em seus domicílios logo após a alta da maternidade. Foram realizadas quatro visitas domiciliares ( $7^{\circ} \stackrel{\circ}{,} 14^{\circ} \stackrel{\circ}{ }, 30^{\circ}$ e $45^{\circ}$ dia pós-parto) para coletar os dados e realizar as intervenções com a finalidade de promover e apoiar o aleitamento materno. Os resultados demonstraram que a maioria das mães eram primíparas, possuíam vínculo empregatício e não receberam orientação no pré-natal sobre amamentação nos dois grupos. Além disso, foi identificada alta frequência no consumo de outros leites na dieta dos lactentes, como complemento ao leite materno no final dos 45 dias de vida e frequente uso de chupeta e/ou mamadeira. $\mathrm{O}$ estudo apontou que as intervenções domiciliares realizadas foram importantes, no entanto, são necessárias novas pesquisas com maior período de tempo para avaliar a eficácia das intervenções.

Palavras-chave: Saúde Materno-Infantil. Aleitamento Materno. Leite Humano. Visita Domiciliar. 


\section{Abstract}

The research aimed to evaluate the effects of home interventions in the continuity of breastfeeding. It is a randomized experimental study with data collection and intervention carried out between January and July 2013. Participants were 20 women (11 in the intervention group and 9 in the control group) who had their children in a public hospital in the city of Santa Maria-RS, Brazil, followed in their homes after hospital discharge. Four home visits were carried out (7th, 14th, 30th and 45th day after delivery) to collect data and conduct interventions in order to promote and support breastfeeding. The results showed that most mothers were primiparous, had formal jobs and had not received guidance on prenatal breastfeeding in both groups. In addition, high frequency was found in the consumption of other types of milk in the diet of infants, in addition to breast milk at the end of the 45 days of life and frequent use of pacifiers and / or bottle. The study found that household interventions were important, however, more research with more time to assess the effectiveness of interventions is necessary.

Key words: Breast Feeding. Maternal and Child Health. Milk Human. Home Visit.

\section{Introdução}

O aleitamento materno exclusivo durante os seis primeiros meses de vida com a complementação de outros alimentos até os dois anos ou mais é importante porque o leite materno confere proteção tanto para o lactente como para a mãe. ${ }^{1}$ A Organização Mundial da Saúde (OMS) e o Fundo das Nações Unidas para a Infância (UNICEF) recomendam e incentivam esta prática, pois a duração do aleitamento materno (AM) está cada vez menor, tornando-se um sério problema de saúde pública em todas as classes e grupos sociais. ${ }^{2}$

Para o sucesso do AM, as mães devem estar de acordo e conscientes da importância do ato de amamentar. A redução da mortalidade infantil; a proteção contra diarreia, infecções respiratórias, hipertensão, alergias, diabetes, hipercolesterolemia e obesidade; a melhora no desenvolvimento e crescimento; a melhor qualidade de vida; os menores custos e principalmente o fortalecimento dos laços entre a mãe e o bebê, são fatores primordiais para a mulher aderir ao aleitamento materno e precisam ser divulgados à população. ${ }^{3}$ 
Levando-se esses aspectos em consideração, o Ministério da Saúde tem incentivado o aleitamento materno na atenção primária, através de estratégias que motivem as mulheres a realizarem tal prática com o intuito de melhorar a saúde das crianças e prevenir doenças futuras. ${ }^{4}$ Dentre as estratégias, destacam-se a Iniciativa Hospital Amigo da Criança, a Rede Cegonha, a Rede Amamenta Brasil e a Estratégia Amamenta e Alimenta Brasil, que realizam ações de promoção do aleitamento materno logo após o parto no ambiente ambulatorial, por profissionais da área.

No entanto, para Martins \& Martins, ${ }^{5}$ o acompanhamento à nutriz no domicílio é visto como mais positivo pelas mães que amamentam, pois as ações prestadas pelos profissionais de saúde nesse ambiente conferem, além de segurança e confiança, maior satisfação às mães. Esse acompanhamento é especialmente importante para as primíparas, pois estas frequentemente sentem dificuldades nos primeiros meses geralmente relacionadas ao ato de amamentar. ${ }^{6,7}$

Com base no exposto, este trabalho teve como objetivo avaliar as repercussões de intervenções domiciliares na continuidade do aleitamento materno. Considerando a importância de manter o aleitamento materno exclusivo até o $6^{0}$ mês de vida, é relevante a realização deste estudo, a fim de identificar as principais dificuldades encontradas pelas mães, os cuidados que as mesmas têm com a lactação e o efeito de intervenções domiciliares na duração do aleitamento materno ao longo dos primeiros meses de vida do lactente.

\section{Metodologia}

Trata-se de estudo experimental não randomizado. A coleta dos dados foi realizada em hospital público municipal de Santa Maria-RS e as intervenções educativas foram realizadas no domicílio das entrevistadas. A pesquisa ocorreu entre janeiro e julho de 2013.

Participaram do estudo 20 nutrizes. A seleção da amostra foi por conveniência, durante o período hospitalar, considerando os critérios de inclusão: mães que tinham dado à luz recentemente (entre 24 e 48 horas pós-parto), que residiam na área urbana do município de Santa Maria-RS e que aceitaram participar do estudo. Os critérios de exclusão adotados foram: mães e filhos com alguma contraindicação para a prática do aleitamento materno (HIV/SIDA), que não queriam amamentar e mães dependentes químicas.

Para todas as mães selecionadas, foi atribuído um número como forma de garantir sigilo e anonimato, e também para a realização do sorteio dos grupos (intervenção e controle). As participantes com números pares foram alocadas no grupo intervenção e as com números ímpares, no grupo controle. Para fins de análise, foram consideradas somente as participantes acompanhadas durante todas as fases da pesquisa (figura 1). Dessa forma, houve 11 participantes 
no grupo intervenção e nove no grupo controle, uma vez que duas participantes deste grupo não foram localizadas após o primeiro contato no hospital. Todas as participantes do estudo foram acompanhadas pela pesquisadora nos seus domicílios logo após a alta da maternidade.

Para fins de descrição das etapas da pesquisa, dividiu-se a coleta de dados do estudo em três fases: Fase 1 - realizada durante o período de internação hospitalar, considerada período de pré-intervenção; Fase 2 - realizada no domicílio, período de intervenção; e Fase 3 - período de julgamento dos dados (figura 1).

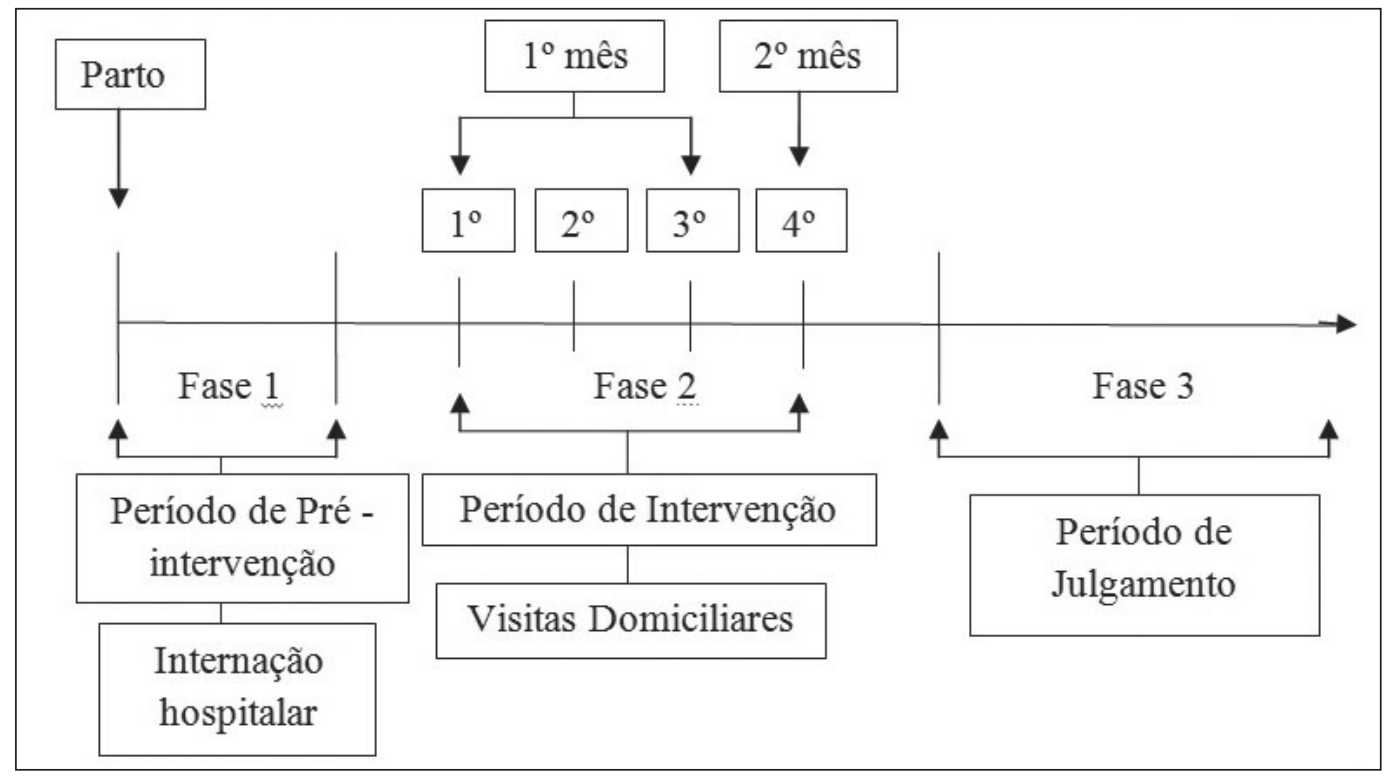

Figura 1. Esquema da metodologia utilizada no trabalho.

Em relação ao grupo intervenção, o período de pré-intervenção ocorreu na maternidade, onde a pesquisadora observou o contato mãe-bebê, a amamentação e as instruções fornecidas pela equipe do hospital, registrando as percepções em formulário próprio. Após, houve o período de intervenção no domicílio das puérperas, iniciando-se no sétimo dia pós-parto.

Foram realizadas quatro visitas domiciliares, sendo três no primeiro mês (7o dia, 14을 dia, $30^{\circ}$ dia) e uma no segundo mês (15ํ dia), segundo a figura 1. Cada visita teve duração média de 30 
minutos, sendo que nas primeiras esse tempo foi maior. Destaca-se que em todas as visitas foi aplicado um questionário semiestruturado, desenvolvido pelas pesquisadoras, com questões abertas e fechadas referentes a amamentação, suas dificuldades, dúvidas e necessidades durante esta fase.

Além disso, na primeira e na última visita, foi realizada a observação da amamentação, utilizando-se como roteiro um formulário adaptado do protocolo de observação e avaliação de mamada do UNICEF, ${ }^{8}$ tendo como aspectos avaliados: a posição da mãe/criança; resposta da dupla; adequação da sucção; anatomia das mamas e estabelecimento de laços afetivos, sendo estes critérios classificados por escores em bom, regular e ruim. Depois da coleta dos dados, realizavamse as intervenções, com base em um planejamento prévio, abordando os temas: importância da amamentação; posicionamento e pega adequada; problemas na lactação; uso de chupeta e/ou mamadeira; mitos e tabus do aleitamento materno; ordenha do leite materno; trabalho versus amamentação e introdução dos alimentos complementares. Como auxílio para abordagem destes assuntos, foram entregues às mães materiais didáticos e ilustrativos, como cartilhas e álbuns seriados, com as devidas orientações.

Em relação ao grupo controle, no período de internação hospitalar foram observados também o contato mãe-bebê, a amamentação e as instruções fornecidas pela equipe do hospital, registrando as percepções em formulário próprio. Além disso, na fase 2 também foram realizadas quatro visitas domiciliares, sendo três no primeiro mês ( $7^{\circ}$ dia, $14^{\circ}$ dia, $30^{\circ}$ dia) e uma no segundo mês (15ํㅜ dia).

Em cada visita, foi aplicado o mesmo questionário semiestruturado do grupo intervenção, desenvolvido pelas pesquisadoras. Da mesma forma, na primeira e na última visita, foi feita a observação da amamentação, utilizando como roteiro o formulário adaptado do protocolo de observação e avaliação de mamada do $\mathrm{UNICEF},{ }^{8}$ mas sem fazer as intervenções.

Posteriormente, os dados foram digitados em um banco no programa Excel e posteriormente analisados no software Statistical Package for the Social Sciences (SPSS), versão 18.0, por meio da estatística descritiva simples (frequência relativa, média e desvio-padrão). A associação entre variáveis foi feita utilizando o teste Exato de Fisher, considerando significante quando $\mathrm{p}<0,005$.

Para atender aos critérios éticos, foram seguidas as recomendações da Resolução CNS no. 466/12, que prescreve a ética na pesquisa com seres humanos..$^{9} \mathrm{O}$ estudo foi aprovado pelo Comitê de Ética em Pesquisa do Centro Universitário Franciscano sob parecer de número 185.769. Os dados foram coletados somente após autorização e assinatura do Termo de Consentimento Livre e Esclarecido (TCLE) pelas participantes. 


\section{Resultados}

Fizeram parte da pesquisa 20 puérperas, 11 no grupo intervenção e nove no grupo controle sendo a média de idade materna 24,7 \pm 4,39 anos (23,36 \pm 4,52 anos e 26,33 \pm 3,84 anos, respectivamente). A tabela 1 apresenta as características da população de estudo em cada grupo, onde é possível observar que, embora haja diferenças entre os grupos, esta não se mostrou estatisticamente significante $(\mathrm{p}<0,05)$. A maioria das mães, tanto no grupo intervenção quanto no grupo controle, eram primíparas, $73 \%(n=8)$ e $67 \%(n=6)$, respectivamente, conforme mostra a tabela 1 .

Tabela 1. Características da população do estudo (grupo controle e grupo intervenção). Santa Maria-RS, 2013.

\begin{tabular}{|c|c|c|c|c|}
\hline \multirow[t]{2}{*}{ Variáveis } & \multicolumn{4}{|c|}{ Grupos } \\
\hline & $\begin{array}{l}\text { Total* } \\
(n=20)\end{array}$ & $\begin{array}{l}\text { Intervenção* } \\
\qquad(\mathrm{n}=11)\end{array}$ & $\begin{array}{l}\text { Controle* } \\
\quad(n=9)\end{array}$ & $\mathrm{p}^{* *}$ \\
\hline \multicolumn{5}{|l|}{ Estado Civil } \\
\hline Vive com o companheiro & $16(80)$ & $10(91)$ & $6(67)$ & \multirow[t]{2}{*}{0,178} \\
\hline Não vive com o companheiro & $4(20)$ & $1(9)$ & $3(33)$ & \\
\hline \multicolumn{5}{|l|}{ Escolaridade } \\
\hline$\geq 8$ anos de estudo & $20(100)$ & $11(100)$ & $9(100)$ & \multirow[t]{2}{*}{$\mathrm{NC}$} \\
\hline$<8$ anos de estudo & $0(0)$ & $0(0)$ & $0(0)$ & \\
\hline \multicolumn{5}{|l|}{ Renda } \\
\hline Até 1 salário-mínimo & $2(10)$ & $2(18,18)$ & $0(0)$ & \multirow{4}{*}{0,228} \\
\hline De 1 a 2 salários-mínimos & $11(55)$ & $4(36,36)$ & $7(78)$ & \\
\hline De 2 a 3 salários-mínimos & $6(30)$ & $4(36,36)$ & $2(22)$ & \\
\hline > 3 salários-mínimos & $1(5)$ & $1(9,1)$ & $0(0)$ & \\
\hline \multicolumn{5}{|l|}{ Possui vínculo empregatício } \\
\hline Sim & $13(65)$ & $7(64)$ & $6(67)$ & \multirow[t]{2}{*}{0,888} \\
\hline Não & $7(35)$ & $4(36)$ & $3(33)$ & \\
\hline
\end{tabular}




\begin{tabular}{|c|c|c|c|c|}
\hline \multirow[t]{2}{*}{ Variáveis } & \multicolumn{4}{|c|}{ Grupos } \\
\hline & $\begin{array}{l}\text { Total* } \\
(n=20)\end{array}$ & $\begin{array}{l}\text { Intervenção* } \\
\qquad(\mathrm{n}=11)\end{array}$ & $\begin{array}{l}\text { Controle* } \\
\qquad(\mathrm{n}=9)\end{array}$ & $\mathrm{p}^{* *}$ \\
\hline \multicolumn{5}{|l|}{ Fumante } \\
\hline $\operatorname{Sim}$ & $1(5)$ & $1(9)$ & $0(0)$ & 0,353 \\
\hline Não & $19(95)$ & $10(91)$ & $9(100)$ & \\
\hline \multicolumn{5}{|l|}{ Tipo de parto } \\
\hline Normal & $14(70)$ & $7(64)$ & $7(78)$ & 0,492 \\
\hline Cesária & $6(30)$ & $4(36)$ & $2(22)$ & \\
\hline \multicolumn{5}{|c|}{ Realização de pré-natal } \\
\hline Sim & $20(100)$ & $11(100)$ & $9(100)$ & $\mathrm{NG}$ \\
\hline Não & $0(0)$ & $0(0)$ & $0(0)$ & \\
\hline \multicolumn{5}{|c|}{ Orientação sobre AM no pré-natal } \\
\hline Sim & $6(30)$ & $3(27)$ & $3(33)$ & 0,769 \\
\hline Não & $14(70)$ & $8(73)$ & $6(67)$ & \\
\hline \multicolumn{5}{|l|}{ Número de filhos } \\
\hline Primíparas & $14(70)$ & $8(73)$ & $6(67)$ & 0,522 \\
\hline Multíparas & $6(30)$ & $3(27)$ & $3(33)$ & \\
\hline
\end{tabular}

*Valores apresentados em n $(\%)$.**Teste Exato de Fisher $(\mathrm{p}<0,05)$.

AM: Aleitamento Materno. NC: não computado.

Em relação ao tipo de parto, o grupo controle apresentou a maior proporção de parto normal (78\%; $\mathrm{n}=7$ ), quando comparado ao grupo intervenção. A maioria das mulheres, em ambos os grupos, vivia com o companheiro, sendo 91\% ( $n=10)$ no grupo de intervenção e $67 \%$ (n=6) no controle. No item "escolaridade", $100 \%(\mathrm{n}=20)$ das mães possuem mais que oito anos de estudo (tabela 1).

Em realção ao vínculo empregatício, a maioria das mulheres trabalha, sendo $64 \%$ (n=7) no grupo intervenção e $67 \%(\mathrm{n}=6)$ no grupo controle. A renda familiar também foi pesquisada e revelou que a maioria recebe de um a dois salários mínimos, tanto no grupo intervenção (36,36\%; n=4) quanto no grupo controle $(78 \%$; $n=7)$. Em relação ao pré-natal, $100 \%(n=20)$ das mães o 
realizaram, porém $73 \%(n=8)$ do grupo intervenção e $67 \%(n=6)$ do controle não haviam recebido nenhuma orientação sobre amamentação. As demais variáveis estão apresentadas na tabela 1 .

Com relação aos fatores que levam ao desmame (tabela 2), foram consideradas as respostas com maior índice de representatividade com relação aos objetivos do estudo. Neste sentido, observou-se que o uso de chupeta ou mamadeira no grupo intervenção foi maior do que no grupo controle, com $73 \%(n=8)$ e $56 \%(n=5)$, respectivamente. No entanto, nenhum dos fatores listados na tabela 2 se apresentou estatisticamente significante.

Tabela 2. Frequência dos fatores que podem levar ao desmame precoce de acordo com os grupos do estudo. Santa Maria-RS, 2013.

\begin{tabular}{|c|c|c|c|c|}
\hline \multirow{2}{*}{$\begin{array}{l}\text { Fatores que } \\
\text { interferem no } \\
\text { desmame* }\end{array}$} & \multicolumn{3}{|c|}{ Grupos } & \multirow[b]{2}{*}{$\mathrm{p}^{* * *}$} \\
\hline & $\begin{array}{l}\text { Total** } \\
(\mathrm{n}=20)\end{array}$ & $\begin{array}{l}\text { Intervenção** } \\
\qquad(\mathrm{n}=11)\end{array}$ & $\begin{array}{c}\text { Controle }{ }^{* * *} \\
(\mathrm{n}=9)\end{array}$ & \\
\hline
\end{tabular}

Conhecimento sobre AM exclusivo

$\begin{array}{lcccc}\text { Sim } & 18(90) & 10(91) & 8(89) & 0,881 \\ \text { Não } & 2(10) & 1(9) & 1(11) & \end{array}$

Uso de chupeta ou mamadeira

$\begin{array}{lllll}\text { Sim } & 13(65) & 8(73) & 5(56) & 0,423 \\ \text { Não } & 7(35) & 3(27) & 4(44)\end{array}$

Uso de protetor de mamilo

$\begin{array}{lrrrr}\text { Sim } & 8(40) & 4(36) & 4(44) & 0,714 \\ \text { Não } & 12(60) & 7(64) & 5(56) & \end{array}$

Orientação de ordenha do LM

Sim

$2(10) \quad 2(18)$

Não $\quad 18(90) \quad 9(82) \quad 9(100)$

Problemas na lactação

$\begin{array}{lcccc}\text { Sim } & 17(85) & 10(91) & 7(78) & 0,413 \\ \text { Não } & 3(15) & 1(9) & 2(22)\end{array}$




\begin{tabular}{|c|c|c|c|c|}
\hline \multirow{2}{*}{$\begin{array}{l}\text { Fatores que } \\
\text { interferem no } \\
\text { desmame* }\end{array}$} & \multicolumn{3}{|c|}{ Grupos } & \multirow[b]{2}{*}{$\mathrm{p}^{* * *}$} \\
\hline & $\begin{array}{l}\text { Total** } \\
(n=20)\end{array}$ & $\begin{array}{l}\text { Intervenção** } \\
\qquad(\mathrm{n}=11)\end{array}$ & $\begin{array}{c}\text { Controle** } \\
(n=9)\end{array}$ & \\
\hline \multicolumn{5}{|c|}{ Leite materno sustenta } \\
\hline Sim & $11(55)$ & $5(45)$ & $6(67)$ & 0,343 \\
\hline Não & $9(45)$ & $6(55)$ & $3(33)$ & \\
\hline \multicolumn{5}{|c|}{ Quem amamenta pode trabalhar fora } \\
\hline Sim & $13(65)$ & $9(82)$ & $4(44)$ & 0,081 \\
\hline Não & $7(35)$ & $2(18)$ & $5(56)$ & \\
\hline \multicolumn{5}{|c|}{ Uso de cremes, pomadas ou sabonete } \\
\hline Sim & $9(45)$ & $4(36)$ & $5(56)$ & 0,391 \\
\hline Não & $11(55)$ & 7 (64) & $4(44)$ & \\
\hline \multicolumn{5}{|c|}{ Conhecimento sobre introdução de AC } \\
\hline Sim & $14(70)$ & $9(82)$ & $5(56)$ & 0,202 \\
\hline Não & $6(30)$ & $2(18)$ & $4(44)$ & \\
\hline
\end{tabular}

*Dados obtidos na Fase 2 antes da realização das intervenções. **Valores apresentados em n(\%). ***Teste Exato de Fisher $(\mathrm{p}<0,05)$.

AM: Aleitamento Materno. LM: Leite Materno. AC: Alimentos Complementares.

No item "orientação de ordenha", $100 \%$ (n=9) das mães do grupo controle não haviam recebido orientação, quando comparados aos $82 \%$ ( $\mathrm{n}=9$ ) do grupo intervenção. Além disso, foi perguntado se as mesmas haviam tido problemas na lactação e constatou-se que $91 \%(\mathrm{n}=10)$ e $78 \%(\mathrm{n}=7)$, do grupo intervenção e do grupo controle, respectivamente, apresentaram algum tipo de problema. Outro item investigado foi se as mães sabiam até quando se deve amamentar exclusivamente e quando se devem introduzir alimentos complementares. Observou-se que a maioria das mães de ambos os grupos relatou ter conhecimento sobre o assunto, não sendo um indicador potencial de risco para o desmame. Outros fatores estão listados na tabela 2.

Quanto ao protocolo de observação de mamada, este não foi analisado em todos os dias de visita, apenas na primeira ( $7^{\circ}$ dia pós-parto) e na última ( $45^{a} \underline{a}$ dia pós-parto). Ressalta-se que, das 20 mães entrevistadas, em apenas uma não foi possível verificar a mamada, sendo este protocolo realizado com 19 mães (11 do grupo intervenção e 8 do grupo controle). Assim, constatou-se que ambos os 
grupos apresentaram bom posicionamento da mãe ao amamentar na primeira observação, sendo que a ocorrência foi maior no grupo intervenção, $100 \%(n=11)$ do que no grupo controle, 87,5\% $(n=7)$. Já na última observação, notou-se melhora no grupo controle quanto à posição, sendo este comportamento observado em $100 \%(\mathrm{n}=19)$ das mães nos dois grupos.

A resposta do bebê durante a amamentação em ambos os grupos foi classificada como "boa", sendo que esta proporção foi maior no grupo controle $(62,5 \% ; n=5)$ quando comparado ao grupo de intervenção $(55 \%$; $=6$ ) na primeira visita. Na última observação, pode-se notar que $100 \%$ (n=11) dos bebês do grupo intervenção e 87,5\% (n=7) do controle apresentaram melhora na observação das respostas. Neste critério, não foram observados comportamentos sugestivos de dificuldades ou ruins, apenas algumas mães foram classificadas como regulares.

A sucção do bebê foi considerada boa nas duas visitas, mas na última no grupo intervenção constatou-se um déficit de sucção, ou seja, $45 \%$ (n=5) dos bebês tinham um escore bom de sucção na primeira visita, quando comparados a 27\% (n=3) dos bebês na última visita. Já o grupo controle foi o que apresentou a melhor sucção com a mesma proporção em ambas as observações, ou seja, $75 \%(\mathrm{n}=6)$.

Quanto à observação de aspectos da anatomia das mamas, o escore "bom" prevaleceu em ambos os grupos e visitas. No grupo controle, $75 \%(n=6)$ das mães apresentaram boa anatomia das mamas e no grupo intervenção, $45 \%(n=5)$ na primeira visita. O resultado foi equivalente entre os grupos na última observação, sendo que no grupo controle o número de mães com boa anatomia permaneceu igual, havendo apenas uma melhora no grupo de intervenção (73\%; n=8). Quanto aos escores "regular" e "ruim", no grupo controle permaneceram iguais em ambas as visitas (25\%) e no grupo de intervenção passaram de $55 \%$ da primeira visita para $27 \%$ na última.

A afetividade durante a amamentação foi semelhante na primeira observação em ambos os grupos, ou seja, $100 \%(\mathrm{n}=8)$ das mães do grupo controle tiveram a afetividade classificada como "boa" ou "regular", enquanto que, no grupo intervenção, $82 \%(n=9)$ das mães apresentaram este comportamento favorável. Já na última visita, constatou-se o crescimento da afetividade no grupo intervenção para $91 \%(\mathrm{n}=10)$.

As prevalências e a continuidade do aleitamento materno durante as quatro visitas realizadas nos dois grupos estudados estão apresentadas nas figuras 2 e 3 . Evidencia-se que, ao $7^{\circ}$ dia de vida, em ambos os grupos ocorreu a maior prevalência de aleitamento materno exclusivo (AME), quando $45 \%(n=4)$ das mães do grupo controle e $64 \%(n=7)$ das mães do grupo de intervenção ofereceram apenas leite materno para o bebê. No $14^{\circ}$ dia de vida, houve um declínio no grupo controle, em que $34 \%$ (n=3) das mães continuaram oferecendo somente leite materno. 


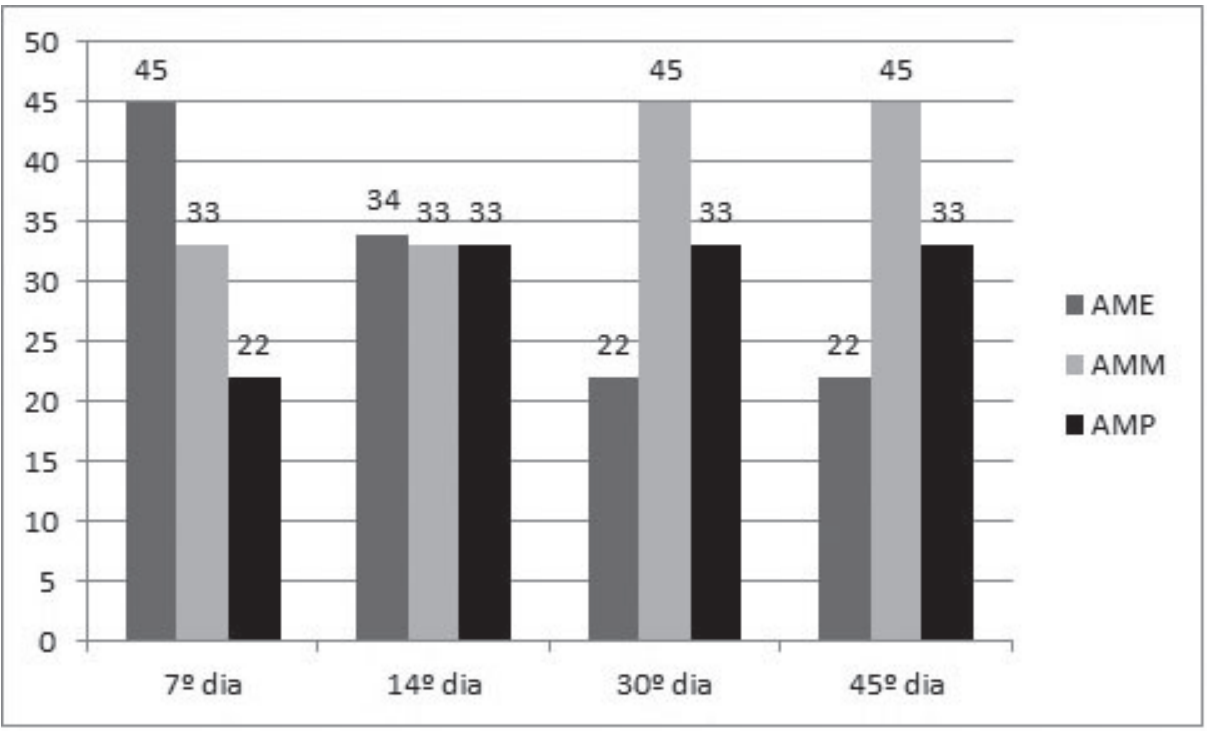

AME: Aleitamento Materno Exclusivo; AMM: Aleitamento Materno Misto; AMP: Aleitamento Materno Predominante.

Figura 2. Prevalência (\%) dos tipos de aleitamento materno conforme as quatro visitas realizadas no grupo controle. Santa Maria-RS, 2013.

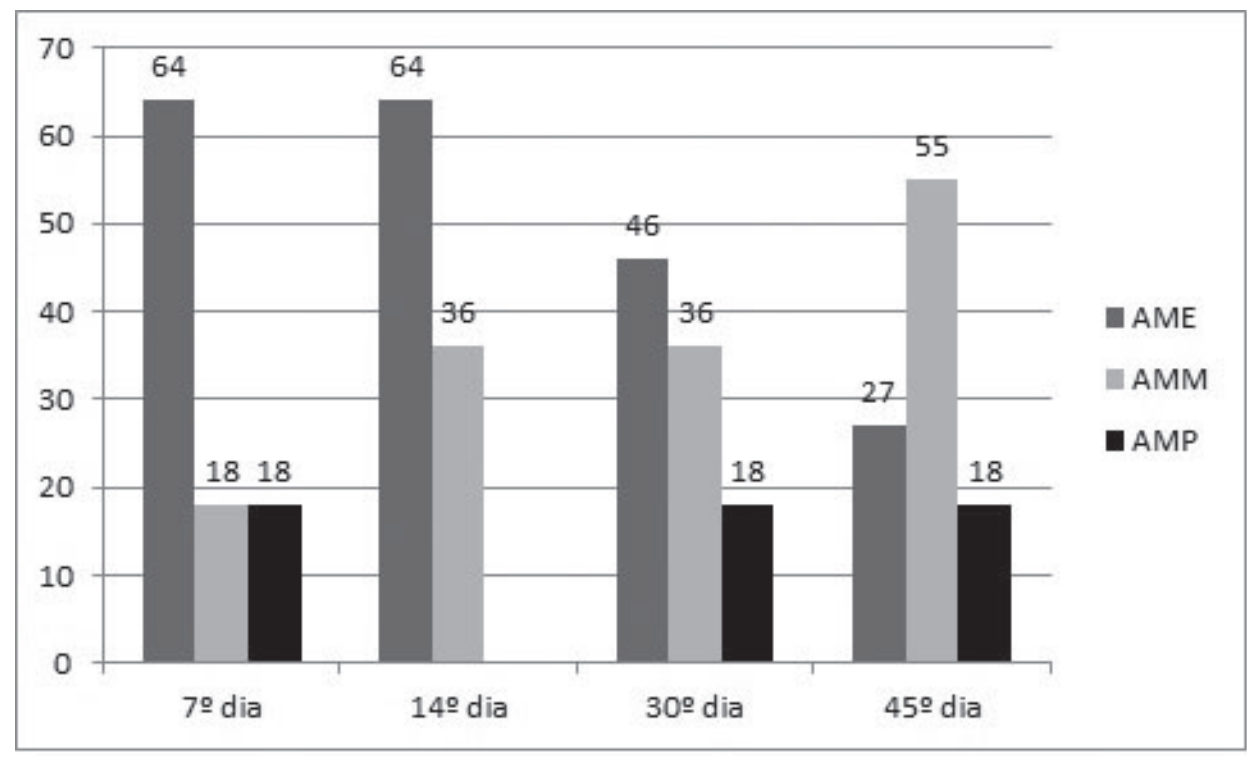

AME: Aleitamento Materno Exclusivo; AMM: Aleitamento Materno Misto; AMP: Aleitamento Materno Predominante

Figura 3. Prevalência (\%) dos tipos de aleitamento materno conforme as quatro visitas realizadas no grupo intervenção. Santa Maria-RS, 2013. 
Já nas duas últimas visitas, $30^{\circ}$ e $45^{\circ}$ dia após o nascimento do bebê, foi verificada maior introdução de outros leites, além do leite materno (AMM) em ambos os grupos, ocorrendo assim diminuição na prevalência do AME. Na última visita, este foi constatado em 22\% (n=2) do grupo controle e $27 \%$ (n=3) no grupo de intervenção.

Quanto ao aleitamento materno predominante (AMP), na primeira visita realizada, 22\% ( $\mathrm{n}=2$ ) das mães do grupo controle haviam introduzido água, chá e/ou suco, sendo esta inserção maior nas outras três visitas (33\%; n=3). Já no grupo intervenção, a prevalência de AMP no 7 o dia de visita foi de $18 \%(\mathrm{n}=2)$, variando conforme mostra a figura 3, e ao 45 a dia de visita manteve-se a mesma proporção. Dessa forma, pode-se notar que a maior prevalência de AME ocorreu nos sete primeiros dias em ambos os grupos, havendo maior introdução de outros leites na dieta dos lactentes ao final dos 45 dias de vida.

\section{Discussão}

A variedade de estratégias existentes, a eficácia de intervenções dos profissionais e a continuidade destas contribuem para o sucesso do aleitamento materno, sendo a realização de intervenções sobre as práticas da amamentação em domicílios uma estratégia que envolve todos os profissionais da saúde, desde o pré-natal até o pós-parto. Com as visitas domiciliares realizadas, observou-se que o aleitamento materno misto ao final dos 45 dias de vida é frequente, com consequente redução da prevalência do aleitamento materno exclusivo em ambos os grupos, sendo esta prática semelhante às encontradas por Audi et al. ${ }^{10}$

A introdução de outros leites artificiais ocorre muito precocemente na dieta dos lactentes, como um complemento ao leite materno, devido às mães estarem inseguras quanto somente à oferta deste. Para a maioria das participantes, esta introdução se deu ao final de 45 dias de vida do bebê (figuras 2 e 3), no entanto, o Ministério da Saúde e a Organização Mundial da Saúde preconizam que o aleitamento materno exclusivo deve ser mantido por no mínimo seis meses. ${ }^{11}$

Quanto ao AMP na primeira semana de vida do bebê, observou-se que 22\% (n=1) e 18\% (n=1), do grupo controle e do grupo intervenção, respectivamente, ofereceram água, chá e/ou suco para os bebês. Coutinho et al..$^{12}$ apontam que o uso de chá para "limpar o intestino" e "evitar cólicas" e a oferta de água para "matar a sede", ainda são práticas culturais muito adotadas por mães e avós nos primeiros dias de vida do bebê.

Quanto aos fatores associados ao desmame, no presente estudo, a maioria das crianças usava chupeta e/ou mamadeira antes dos dois meses de idade (tabela 2). Warkentin et al., ${ }^{13} \mathrm{em}$ seu estudo com 636 crianças, verificaram que 79,8\% usavam chupeta antes dos três meses de idade, resultado semelhante ao da presente pesquisa. Além disso, diversos estudos apontam expressiva associação 
entre uso de chupeta e/ou mamadeira e desmame, pois o uso destes pode diminuir o reflexo de sucção devido ao efeito chamado de "confusão de bicos". Isso faz com que a criança rejeite o peito da mãe e, consequentemente, mame menos, ocorrendo assim o desmame precoce. ${ }^{14}$

O uso de chupeta e/ou mamadeira também está associado à inadequada sucção do bebê, fator que chamou atenção no momento da observação da mamada neste estudo, pois notou-se expressivo déficit na sucção no grupo intervenção entre a primeira e a última visita. Ressalta-se, no entanto, que mesmo com as intervenções realizadas, as mães também são influenciadas pelo ambiente externo, principalmente por fatores socioeconômicos e culturais, como: conhecimento da mãe e familiares, vivência com os avós, renda familiar, orientações dos demais profissionais de saúde, entre outros. Dessa forma, é necessário que a população e os profissionais de saúde sejam mais informados sobre esses efeitos para melhor orientar as mães, especialmente no pré-natal, pós-parto e alta domiciliar. ${ }^{14}$

Além da sucção dos bebês, verificou-se a posição da dupla mãe/bebê e contatou-se que, ao final das observações, $100 \%$ das mães de ambos os grupos apresentaram boa posição. Este fato difere do estudo de Carvalhaes \& Corrêa ${ }^{15}$ realizado com 50 duplas observadas entre 18 e 30 horas de vida no alojamento conjunto, no qual os autores observaram que $68 \%(n=34)$ das mães apresentaram um escore bom. Assim, ressalta-se que a posição não foi um motivo que poderia levar ao desmame precoce, possivelmente porque, no decorrer dos dias, a mãe possui maior segurança e confiança para amamentar seu filho.

Quanto à resposta do bebê durante a amamentação, não foi observado nenhum comportamento sugestivo de dificuldades, diferindo do estudo de Carvalhaes \& Corrêa, ${ }^{15}$ segundo o qual 12\% (n=6) dos bebês apresentaram escores ruins. Quanto à resposta "boa” dos bebês neste estudo, notou-se melhora no grupo intervenção da primeira para a última visita, fato associado às intervenções realizadas durante este período e também porque, com o passar dos dias, o bebê vai aprendendo a mamar, sentindo-se mais seguro para tal prática.

Para finalizar, o escore "bom" foi o mais frequente em ambos os grupos e visitas, tanto na observação de aspectos da anatomia das mamas, como na afetividade entre as duplas. Este fato corrobora os resultados encontrados por Carvalhaes \& Corrêa, ${ }^{15}$ onde $82 \%(n=41)$ das duplas apresentaram bons laços afetivos e 78\% (n=39) das mulheres apresentaram boa anatomia das mamas.

Assim sendo, nota-se a importância de oferecer suporte além do âmbito hospitalar para as nutrizes, a fim de aumentar e melhorar a prática da amamentação, com apoio de todos os profissionais da saúde. O presente estudo teve algumas limitações, como o tamanho da amostra, a não realização de um estudo piloto, a falta de um questionário validado sobre os fatores de risco para o desmame e o curto período de tempo para realização das intervenções domiciliares. 
Para estimular o aleitamento materno preferencialmente exclusivo até o sexto mês, seria necessário um acompanhamento domiciliar por no mínimo quatro meses pós-parto. Quanto ao tipo de intervenção realizada, acredita-se que esta seja uma estratégia muito eficaz, pois segundo relatos das mães e achados deste e de outros estudos, é no domicílio que as mães se sentem mais inseguras em relação à amamentação. Tendo em vista isso, fazem-se necessárias novas pesquisas sobre o assunto abordado, levando-se em consideração essas limitações.

\section{Conclusões}

Os resultados deste estudo mostraram que a continuidade do aleitamento materno persistiu em ambos os grupos ao final dos 45 dias de vida dos bebês. Observa-se, no entanto, que mesmo com as intervenções domiciliares, a percentagem de mães que amamentaram seus filhos exclusivamente até o final das visitas foi muito baixa quando comparada à primeira visita domiciliar. A introdução de outros leites, como complemento do leite materno, teve alta frequência em todos os dias de visitas nos dois grupos investigados. Além disso, a diminuição do AME pode estar associada à alta frequência do uso de chupeta e/ou mamadeira, água, chás e sucos, bem como à inadequada sucção do bebê no momento da amamentação.

No entanto, a pesquisa mostrou que as intervenções foram importantes, pois as mães, especialmente as primíparas, mostraram-se bastante inseguras quanto à amamentação, e esta estratégia contribuiu para sanar as dificuldades encontradas pelas mesmas. Além disso, as intervenções tiveram grande impacto quando se analisaram os aspectos no momento da amamentação, tendo crescente melhora na última observação. As intervenções, além de promoverem e incentivarem a continuidade do aleitamento materno, ajudaram a reduzir os fatores contribuintes para o desmame.

Ressalta-se, assim, a importância das orientações às mães não só no âmbito domiciliar, mas desde o início do pré-natal e durante a internação hospitalar. Esse tipo de estratégia poderá ser útil para melhorar a qualidade de vida e saúde do grupo materno-infantil, fortalecer o vínculo mãe/bebê e aumentar a continuidade do aleitamento materno, devido às inúmeras vantagens que o mesmo confere ao binômio mãe/bebê.

\section{Referências}

1. Antunes LS, Antunes LAA, Corvino MPF, Maia LC. Amamentação natural como fonte de prevenção em saúde. Ciên. Saúde Coletiva2008; 13(1):103-109.

2. Organização Mundial de Saúde. Promoção e apoio ao aleitamento materno: o papel especial dos serviços materno infantis. Uma declaração conjunta. Genebra: UNICEF; 1989. 
3. Brasil. Ministério da Saúde. Saúde da criança: nutrição Infantil: aleitamento materno e alimentação complementar. Brasília: Ministério da Saúde; 2009. Caderno de Atenção Básica, 23.

4. Albernaz E, Victora CG. Impacto do aconselhamento face a face sobre a duração do aleitamento exclusivo: um estudo de revisão. Rev. Panam. Salud Publica2003;14(1):17-24.

5. Martins ADM, Martins EF. Assistência de enfermagem domiciliar no puerpério para garantir sucesso no aleitamento materno: relato de caso. Revista Brasileira de Ciências da Saúde. 2008; 3(15):82-93.

6. Stevens B, Guerriere D,McKeever P, CroxfordR,Miller KL, Watson-MacDonell J.Economics of home vs. Hospital breastfeeding support for newborns. J.Nurs. Adv. 2006; 53(2):233-243.

7. Terra DLH; Okasaki ELFJ. Compreensão de puérperas primíparas sobre os cuidados domiciliares com o recém-nascido. Rev. Enferm. UNISA 2006; 7:15-20.

8. Fundo das Nações Unidas para a Infância. Iniciativa Hospital Amigo da Criança: revista, atualizada e ampliada para o cuidado integrado: Módulo 3: promovendo e incentivando a amamentação em um Hospital Amigo da Criança: Curso de 20 horas para equipes de maternidade. Brasília: Ministério da Saúde, Organização Mundial da Saúde; 2009.

9. Brasil. Resolução CNS no 466, de 12 de dezembro de 2012. Diário Oficial da União, 13 jun. 2012, Seção I, p. 59-62.

10. Audi CAF, Corrêa MAS, Latorre MRDO. Alimentos complementares e fatores associados ao aleitamento materno e ao aleitamento materno exclusivo em lactentes até 12 meses de vida em Itapira, São Paulo, 1999. Rev. Bras. Saúde Matern. Infant.2003; 3(1):85-93.

11. World Health Organization. The optimal duration of exclusive breastfeeding. Report of an expert consultation. Geneva: WHO; 2001. Disponível em: http://whqlibdoc.who.int/hq/2001/WHO_ NHD_01.09.pdf

12. Coutinho SB, Lima MC, Ashworth A, Lira PIC.Impacto de treinamento baseado na Iniciativa Hospital Amigo da Criança sobre práticas relacionadasà amamentação no interior do Nordeste. Jornal de Pediatria 2005; 81(6):471-7.

13. Warkentin S, Viana KJ, Zapana PM, Aguiar JAA, Taddei JJAC. Fatores associados à interrupção do aleitamento materno exclusivo antes dos seis meses em crianças matriculadas em creches públicas e filantrópicas do Município de São Paulo, Brasil. Nutrire 2012; 37(2):105-117.

14. Lamounier JA. O efeito de bicos e chupetas no aleitamento materno. Jornal de Pediatria. 2003; 79(4):284-286.

15. Carvalhaes MABL, Corrêa CRH. Identificação de dificuldades no início do aleitamento materno mediante aplicação de protocolo. Jornal de Pediatria. 2003; 79(1):13-20. 
